\title{
Virtual Indication of the Torque for a Marine Gas Turbine
}

\author{
Filip Niculescu \\ Romanian Research and Development Institute for Gas Turbines COMOTI \\ filip.niculescu@comoti.ro \\ Mirela Letitia Vasile \\ Romanian Research and Development Institute for Gas Turbines COMOTI \\ mirela.vasile@,comoti.ro \\ George Balan \\ Romanian Research and Development Institute for Gas Turbines COMOTI \\ george333@gmail.com
}

\section{Adrian Săvescu}

Romanian Research and Development Institute for Gas Turbines COMOTI adrian.savescu@.comoti.ro

\section{Roxana Nicolae}

Romanian Research and Development Institute for Gas Turbines COMOTI roxana.nicolae@,comoti.ro

\begin{abstract}
Gas turbines are used in marine applications where high propulsion power is required compared to engine size and mass. In some cases, the torque and engine power developed cannot be measured with a special transducer implemented in applications or if there are indications, they need to be compared with the calculated torque indication. For this purpose, we developed in the engine control software application a mathematical model for calculating and displaying the torque and power developed by the engine. Through comparisons in the tests with the engine on the test bench, this mathematical model was refined. At this time the comparative sampled data can be used as a virtual indication of torque in cases where this is necessary.
\end{abstract}

Keywords. turbines, torque, marine technology, automation, command and control systems.

\section{Introduction}

A gas turbine propulsion system for marine applications $[1,2]$ converts the primary form of energy (burnt fuel) into mechanical power, for ensuring the necessary shaft torque for spinning a ship's propellers. 
The paper presents the virtual indication for a ST40M gas turbine torque, realised during the bench tests for retrofitting works on a navy ship [3]. The new engines are delivered without the electronic control system [4]. A customized automation system [5,6] was designed and implemented within the Romanian Research and Development Institute for Gas Turbines COMOTI. This system provides undeniable advantages comparing to the standard electronic control system that can be acquired from gas turbine manufacturer, since it is able to calculate and monitor some very important parameters, such as inter-turbine temperature, torque and power. The FADEC system from manufacturer is a small box that only controls the engine speed.

The gas turbine (Fig.1) consists of a three-stage axial compressor and a three-stage centrifugal compressor, combustion chamber, two-stage power turbine, fuel system, ignition system, lubrication system, accessory box, wiring and transducers [7].

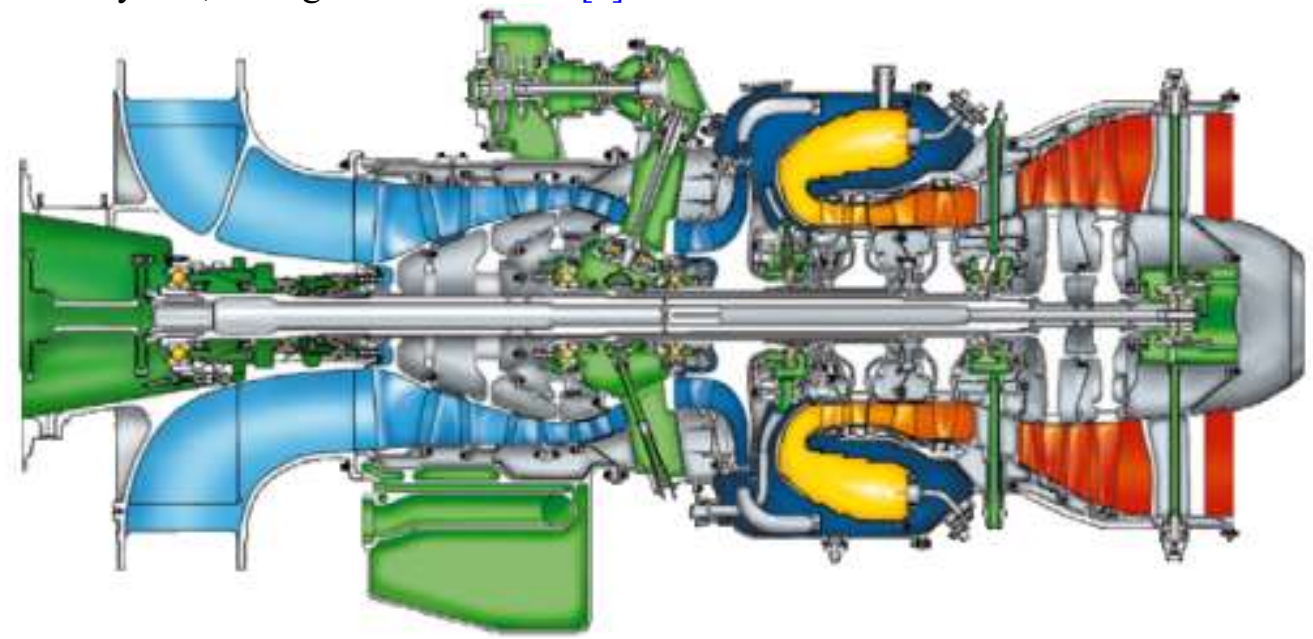

Fig.1 . Section through the ST40M gas turbine [8]

\section{ST40M gas turbine tests and control equations}

In order to establish the performances, the gas turbine was installed on the test bench and was subjected to the necessary working regimes (fig.2).

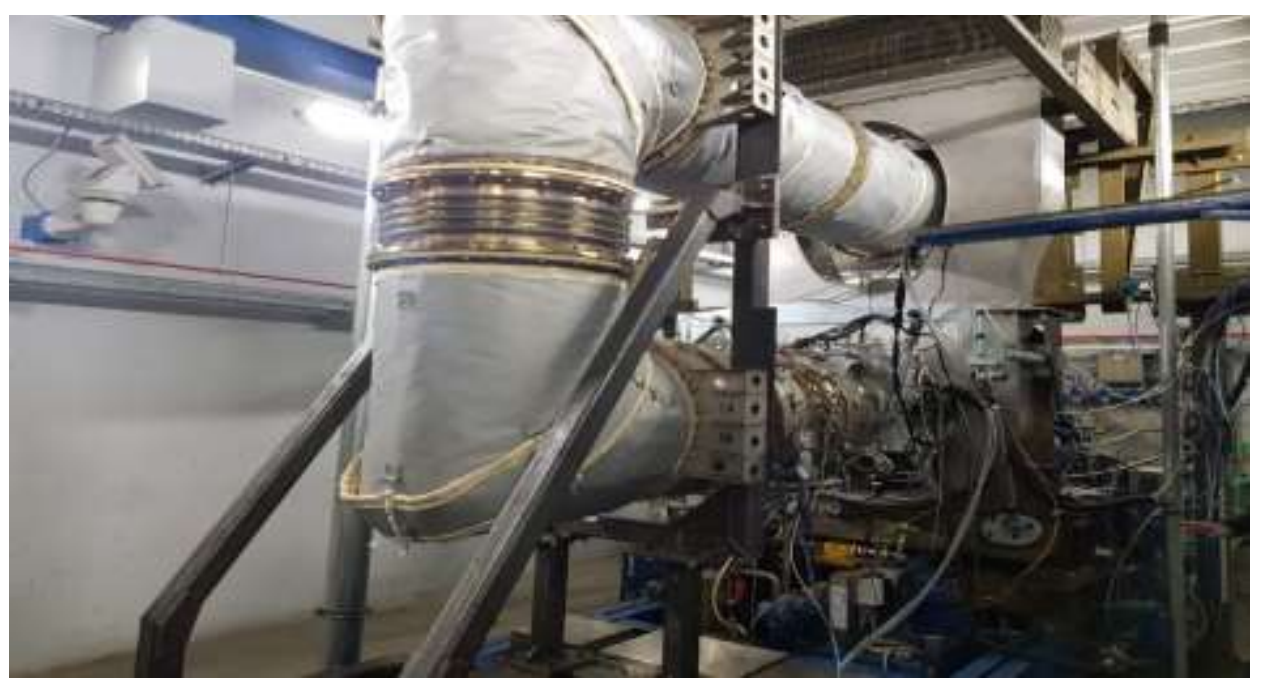

Fig.2 ST40M gas turbine installed on the test bench 
The control and monitoring of the gas turbine are performed by an automatic electronic system composed of a local control panel connected to the gas turbine and to the junction boxes, and for the remote control it is connected to a computer. Commands can be given both locally via the operator panel mounted on the door of the local control panel and remotely via the interface programmed in the remote control computer. The junction boxes meet the specific parameters of the gas turbine auxiliary installations [6].

The equations used in determining torque and power are those used to calculate the torque and power of a gas turbine, customized for ST40M.

1. Calculation of the inter turbines temperature in degrees Kelvin and in degrees Celsius ITTk si ITTe:

$$
\begin{aligned}
& I T T_{k}=R T_{I T T} \times\left(T_{1}+273\right)\left[{ }^{\circ} \mathrm{K}\right] \\
& I T T_{c}=I T T_{k}-273\left[{ }^{\circ} \mathrm{C}\right]
\end{aligned}
$$

The $R T_{I T T}$ factor has different expressions for corrected high pressure compressor speed values, $\mathrm{NH}_{\mathrm{C}}$ :

- a) $\mathrm{NH}_{\mathrm{C}}<26800 \mathrm{rpm}$

$$
R T_{I T T}=8.065-6.146 \times 10^{-4} \times N H_{C}+1.615 \times 10^{-8} \times N H_{C}{ }^{2}
$$

- b) $\mathrm{NH}_{\mathrm{C}}>26800 \mathrm{rpm}$

$$
R T_{\text {ITT }}=15.8786-11.02 \times 10^{-4} \times N H_{C}+2.3457 \times 10^{-9} \times N H_{C}{ }^{2}
$$

\section{Calculation of the air flow Ga :}

$$
\begin{aligned}
& \boldsymbol{G}_{\boldsymbol{a}}=\frac{\boldsymbol{P}_{\mathbf{0}}}{\mathbf{1 0 3 2 . 5}} \times \sqrt{\frac{\mathbf{2 8 8}}{\boldsymbol{T}_{\mathbf{1}}+273}} \times \boldsymbol{G}_{\boldsymbol{a c}}[\mathrm{kg} / \mathrm{s}] \\
& P_{0}=P_{1}+P D A / 10[\mathrm{bar}]
\end{aligned}
$$

The Gac flow has different expressions for the corrected low pressure compressor speed values $\mathrm{NL}_{\mathrm{C}}$ :

- a) $\mathrm{NL}_{\mathrm{C}}<20000 \mathrm{rpm}$

$$
G_{a c}=4.44-3.125 \times 10^{-4} \times N L_{C}+2.875 \times 10^{-8} \times N L_{C}{ }^{2}
$$

- b) $23000 \mathrm{rpm}>\mathrm{NL}_{\mathrm{C}}>20000 \mathrm{rpm}$

$$
G_{a c}=26.79-21.55 \times 10^{-4} \times N L_{C}+6.5 \times 10^{-8} \times N L_{C}{ }^{2}
$$

- c) $\mathrm{NL}_{\mathrm{C}}>23000 \mathrm{rpm}$

$$
G_{a c}=11.89-8.811 \times 10^{-4} \times N L_{C}+3.778 \times 10^{-8} \times N L_{C}{ }^{2}
$$

\section{Calculation of the fuel flow Gc:}

$\boldsymbol{G}_{\boldsymbol{c}}=\frac{\boldsymbol{P}_{\mathbf{0}}}{\mathbf{1 0 3 2 . 5}} \times \sqrt{\frac{288}{\boldsymbol{T}_{\mathbf{1}}+273}} \times \boldsymbol{G}_{c c}[\mathrm{~kg} / \mathrm{s}]$

The Gcc flow has different expressions for the corrected low pressure compressor speed values $\mathrm{NH}_{\mathrm{C}}$ :

a) $\mathrm{NH}_{\mathrm{C}}<26800 \mathrm{rpm}$ 
$G_{c c}=0.8866-8.679 \times 10^{-5} \times N H_{C}+2.227 \times 10^{-9} \times N H_{C}{ }^{2}$

- b) $\mathrm{NH}_{\mathrm{C}}>26800 \mathrm{rpm}$

$$
G_{c c}=2.725-2.264 \times 10^{-4} \times N H_{C}+4.976 \times 10^{-9} \times N H_{C}{ }^{2}
$$

4. Calculation of the parameters Gaca and ALFA:

$G_{\text {aca }}=0.9935 \times R G_{g} \times G_{a}[\mathrm{~kg} / \mathrm{s}]$

$A L F A=\frac{G_{a c a}}{14.5 \times G_{c}}$

The $R G c$ factor has different expressions for the corrected low pressure compressor speed values $\mathrm{NL}_{\mathrm{C}}$ :

- a) $\mathrm{NL}_{\mathrm{C}}<20000 \mathrm{rpm}$

$$
R G_{c}=0.78-5.875 \times 10^{-6} \times N L_{C}+2.812 \times 10^{-10} \times N L_{C}{ }^{2}
$$

- b) $23000 \mathrm{rpm}>\mathrm{NL}_{\mathrm{C}}>20000 \mathrm{rpm}$

$$
R G_{c}=4.897-4.505 \times 10^{-4} \times N L_{C}+1.222 \times 10^{-8} \times N L_{C}{ }^{2}
$$

- c) $\mathrm{NL}_{\mathrm{C}}>23000 \mathrm{rpm}$

$$
R G_{c}=1.0
$$

\section{Calculation of the enthalpy $H$ :}

$$
\begin{aligned}
& H_{I T T}=0.6889+0.2354 \times I T T_{k}+3.21 \times 10^{-5} \times I T T_{k}^{2}[\mathrm{kcal} / \mathrm{kg}] \\
& \operatorname{HITT}_{a}=4.089+0.2181 \times \operatorname{ITT}_{k}+2.765 \times 10^{-5} \times \operatorname{ITT}_{k}{ }^{2}[\mathrm{kcal} / \mathrm{kg}] \\
& \text { HITT }_{a m}=\frac{15.5 \times \text { HITT }_{g}+14.5 \times(A L F A-1) \times H_{I T T}}{1+14.5 \times A L F A}[\mathrm{kcal} / \mathrm{kg}] \\
& H T 6 M_{g}=0.6889+0.2354 \times(\mathrm{T} 6 \mathrm{M}+273)+3.21 \times 10^{-5} \times(T 6 M+273)^{2}[\mathrm{kcal} / \mathrm{kg}] \\
& H T 6 M_{a}=4.089+0.2181 \times(\mathrm{T} 6 \mathrm{M}+273)+2.765 \times 10^{-5} \times(\mathrm{T} 6 \mathrm{M}+273)^{2}[\mathrm{kcal} / \mathrm{kg}] \\
& H T 6 M_{a m}=\frac{15.5 \times H T 6 M_{g}+14.5 \times(A L F A-1) \times H T 6 M_{a}}{1+14.5 \times A L F A}[\mathrm{kcal} / \mathrm{kg}]
\end{aligned}
$$

6. Calculation of the power and torque:

$$
\begin{aligned}
& G_{g}=G_{a c a}+G_{c}[\mathrm{~kg} / \mathrm{s}] \\
& W T P_{c}=4.185 \times 1.03 \times G_{g} \times\left(H I T T_{a m}-H T 6 M_{a m}\right)[\mathrm{kW}] \\
& M T P_{c}=9549.6 \times W T P_{c} / N T P[\mathrm{Nm}]
\end{aligned}
$$

\section{Implementing the equation in the monitoring and control program}

The values obtained by calculation are displayed in the hot start screen of the gas turbine. This screen, designed in the PLC dedicated programming software, Proficy Machine Edition [9], in the original form is shown in figure 3 . 


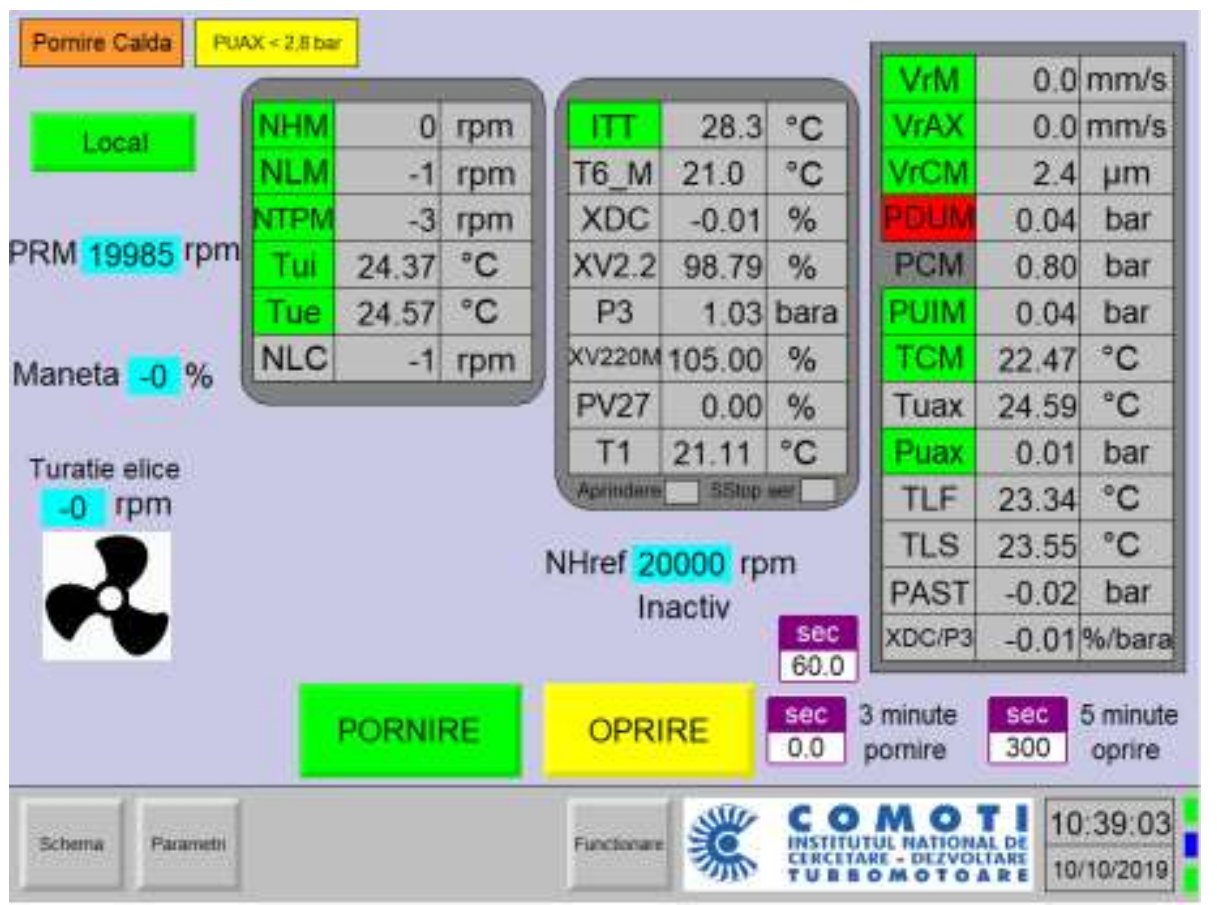

Fig.3 The initial „Hot start” screen

We modified this screen [6] to display the calculated MTPc torque and the calculated WTPc power in the lower left corner, simultaneously with the measured torque and the measured Pkw power displayed at the top of the screen (figure 4).

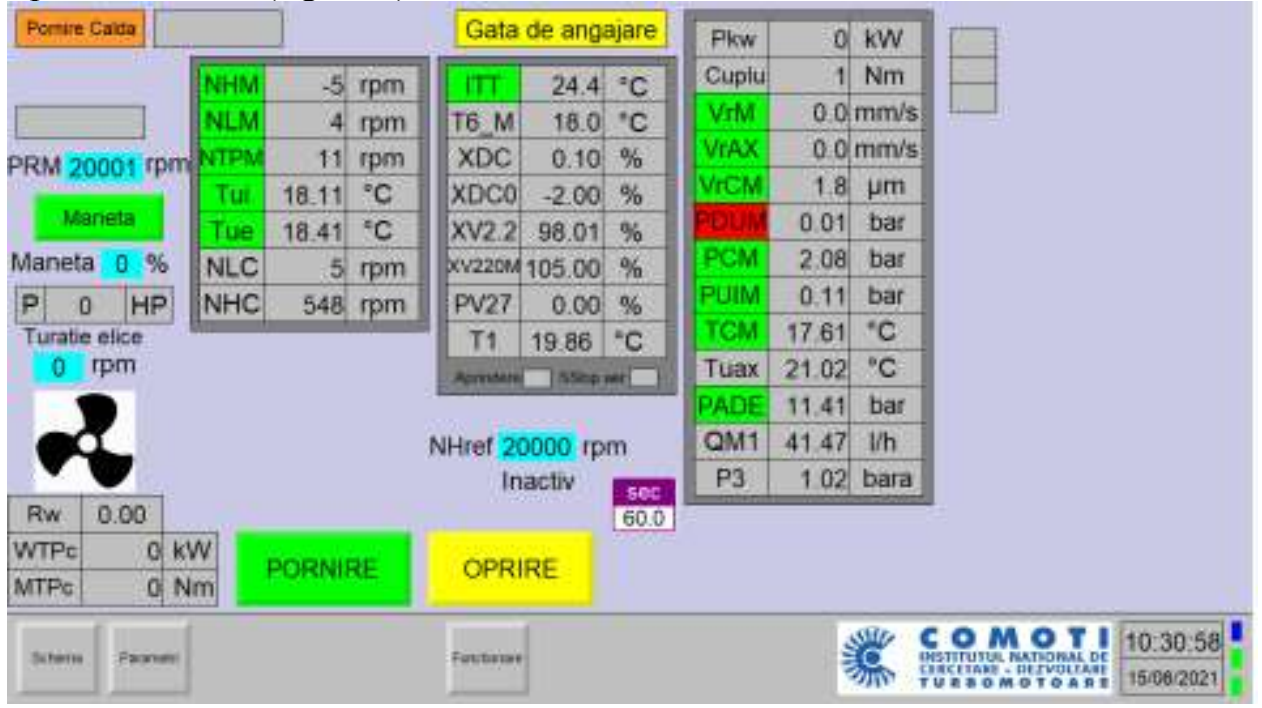

Fig.4 The final „Hot start” screen

Besides the two calculated parameters, the ratio between the calculated power and the real power, $\mathrm{Rw}$ is also displayed. We recorded these data in the data file of each bench sample, with aid of the Versamax PLC [10], in figure 5 being presented the selection referring to the parameters of the equations by which the power and the torque are calculated. 


\begin{tabular}{|c|c|c|c|c|c|c|c|c|c|c|c|}
\hline GAC & $\mathrm{Ga}$ & GCC & Ge: & $R G g$ & Gg & ALFA & HIITam & HT6Mam & WTPe & MTPe & $\mathrm{Ry}$ \\
\hline 4.5919 & 4.4444 & 0.041 & 0.0397 & 0.7495 & 3.3493 & 5.7502 & 166.1474 & 163.4223 & 40.6781 & 116.7778 & 0.6993 \\
\hline 4.5902 & 4.443 & 041 & 0.0397 & 0.7495 & 3.3483 & 748 & 166.1536 & 163.4338 & 40.5883 & 116.6308 & 0.6962 \\
\hline 4.5902 & 443 & .041 & 0.0397 & 0.7495 & 83 & 748 & 1661536 & 163.4 & 40.5883 & 116.6308 & 0.6962 \\
\hline 4.5902 & 4.443 & 0.041 & 0.0397 & 0.7495 & 3.3483 & 748 & 166.1536 & 163.4338 & 40,5883 & 116. & 0.6962 \\
\hline 45902 & 4.4442 & 0.041 & 0.0397 & 0.7495 & 3.3491 & 748 & 166.1534 & 163.4444 & 40.4383 & 1160 & 0.6936 \\
\hline 4.5902 & 4.4442 & 0.041 & 0.0397 & 0.7495 & 3.3491 & 5.748 & 1661534 & 163.4444 & 40.4383 & $116 x$ & 0.6966 \\
\hline 4.5902 & 4.4442 & 0.041 & 0.0397 & 0.7495 & 3.3491 & 5.748 & 166.1534 & 163.4444 & 40.4383 & 116. & 5966 \\
\hline 4.5902 & 4.4442 & 0.041 & 0.0397 & 0.7495 & 3.3491 & 5.748 & 166.1534 & 163.4444 & 40.4383 & 116.0894 & 0.6966 \\
\hline 4.5914 & 4.4429 & 0.041 & 0.0397 & 0.7495 & 3.3481 & 5.7495 & 166.1565 & 163.4439 & 40.479 & 115.9855 & 0.6961 \\
\hline 45914 & 4.4429 & 0.041 & 0397 & 0.7495 & 3.3481 & 5.7495 & 166.1565 & 163.4439 & 40.479 & 115.9855 & 0.6961 \\
\hline 4.5914 & 4.4429 & 0.041 & 0397 & 0.7495 & 3481 & 7495 & 166.1565 & 163.4439 & 40.479 & 1159855 & 0.6961 \\
\hline 4.5923 & 452 & .041 & 0397 & 7495 & 99 & 7506 & 166.1524 & 163.4329 & 0.6032 & 116.2679 & 6983 \\
\hline 4.5923 & 452 & 041 & 397 & 3 & 99 & 7506 & 166 & 16 & 032 & 116 & 245 \\
\hline 3 & 52 & 041 & 7 & & & & 4 & & & 79 & 0.6945 \\
\hline 4.5923 & 4.4452 & 0.041 & 0397 & 0.7495 & 3.3499 & 5.7506 & 166.1524 & 163.4 & 40.6032 & 116.2679 & 0.6945 \\
\hline 4591 & 4.4449 & 0.041 & 0.0397 & 0.7495 & 3.3496 & 5.749 & 166.1499 & 163.4441 & 40.3963 & 115.8586 & 0.6905 \\
\hline 4.591 & 4.4449 & 0.041 & 0.0397 & 0.7495 & 3.3496 & 5.749 & 166.1499 & 163.4441 & 40.3963 & 115.8586 & 0.6907 \\
\hline 4.591 & 4.4449 & 0.041 & 0.0397 & 0.7495 & 3.3496 & 5.749 & 166.1499 & 163.4441 & 40.3963 & 115.8586 & 0.6907 \\
\hline
\end{tabular}

Fig.5 Saved data on test bench

The graph of the ratio between the calculated power and the measured power, Rw, during the complete tests with the gas turbine (fig.6,7), shows the cases in which the power calculation is exact $(\mathrm{Rw}=1)$.

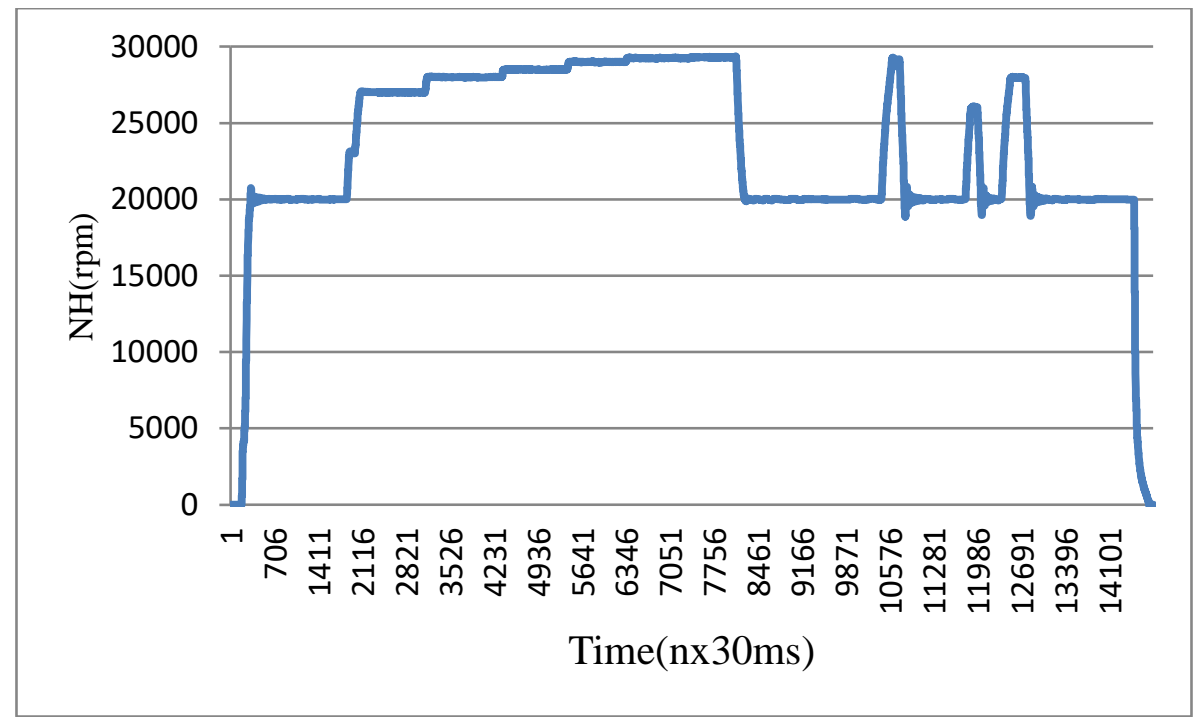

Fig.6 Variation of the high pressure compressor speed, NH, to a complete test 


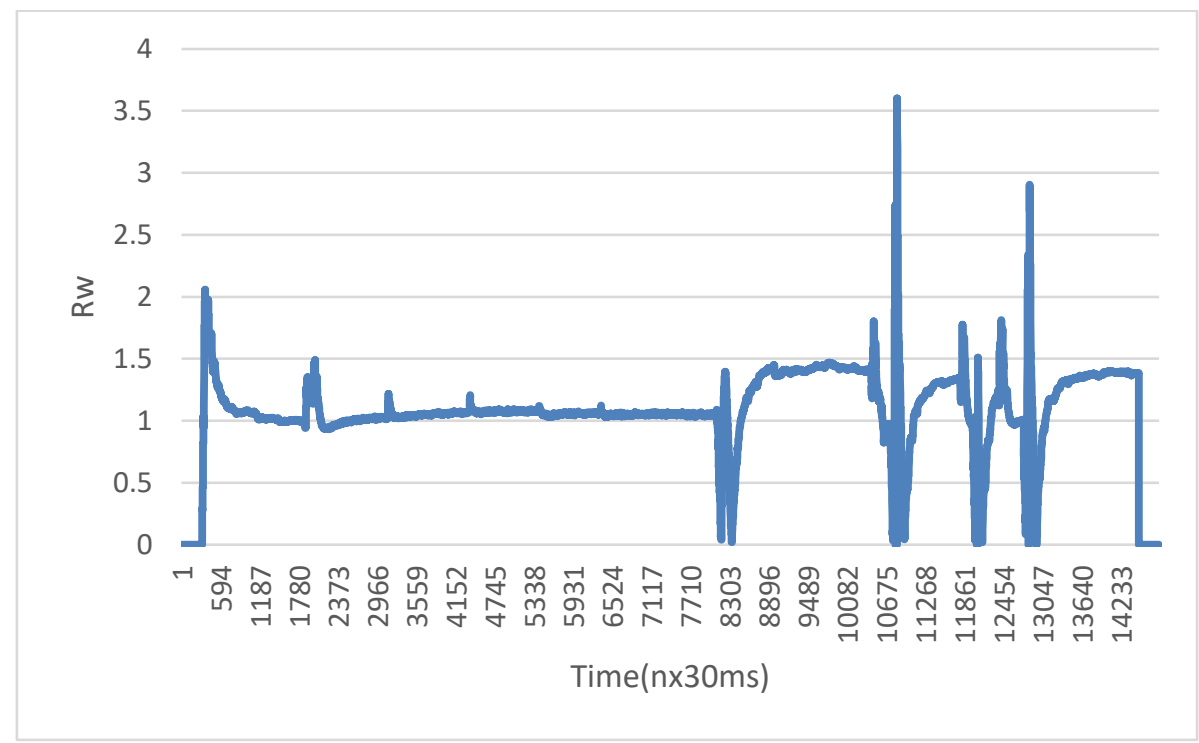

Fig.7 Variation of the Rw ratio at the test in figure 6

Analyzing the graphs in figures 7 we observe the following:

a) The calculated power reproduces well the power measured at stable engine speeds $(\mathrm{Rw}=1)$;

b) In transient regime the calculated power has very large deviations from the measured power, $\Delta \mathrm{Rw}=-1 /+3.5$

c) After decelerating the engine, at idle $\mathrm{NH}=20000 \mathrm{rpm}$, there is a difference of +0.5 compared to the unit value of the ratio Rw;

d) The large deviation from the unit value of Rw, at stationary regimes, takes place at idle regime $\mathrm{NH}=20000 \mathrm{rpm}$, when the power developed by the gas turbine is relatively small (WTP $=60 \mathrm{Kw})$ so it can be ignored, the interest being for correct power calculation at speeds close to the nominal speed $(\mathrm{WTP}=4000 \mathrm{~kW})$.

\section{Conclusions}

The use of the calculated torque instead of the measured one can be done under certain conditions. At transient regimes or deceleration decelerations the deviations are significant, but at low values of the developed power. The equations introduced in the developed software application can be used successfully as an indicator of the power developed at speeds close to the nominal power regime.

\section{References}

[1] B. MacIsaac and R. Langton, "Chapter 9 Marine Propulsion Systems", in: Gas Turbine Propulsion Systems, John Wiley \& Sons, 2011, pp. 195-225. DOI: 10.1002/9781119975489.ch9.

[2] A. Sayma, "Gas Turbines for Marine Applications", Encyclopedia of Maritime and Offshore Engineering, pp. 1-10, 2017. DOI: 10.1002/9781118476406.emoe227.

[3] "Forțele Navale Române", Navy.ro, 2021, https://www.navy.ro/despre/organizare/dateF221.php.

[4] C.G. Hodge, "The Integration of Electrical Marine Propulsion Systems", International Conference on Power Electronics Machines and Drives, 2002. DOI: 10.1049/cp:20020081.

[5] F. Niculescu, C. Borzea, A. Savescu, A. Mitru and M. Vasile, "Automation and Electronic 
Control of Marine Gas Turbine Engine for Ship Revamp", Technium: Romanian Journal of Applied Sciences and Technology, vol. 2, no. 4, pp. 98-108, 2020. DOI: 10.47577/technium.v2i4.923.

[6] F. Niculescu, C. Borzea, I. Vlăducă, A. Mitru, M. Vasile, A. Țăranu, and G. Dediu, "Automation Control for Revamping the Propulsion System of a Navy Frigate", UPB Scientific Bulletin, Series D Mechanical Engineering, vol. 83, iss. 1, 2021, pp. 257-268. ISSN 1454-2358.

[7] *** ST40M Engine - Technical description.

[8] *** ST40M Marine Gas Turbine - Installation Manual.

[9] *** Proficy Machine Edition, GE Fanuc Automation, GFK-1868P, 2011

[10] *** VersaMax PLC, User's Manual, GE Fanuc Automation, GFK-1503C, 2001. https://www.qualitrol.com/storage/wysiwyg/gfk1503cusermanual 1.pdf. 